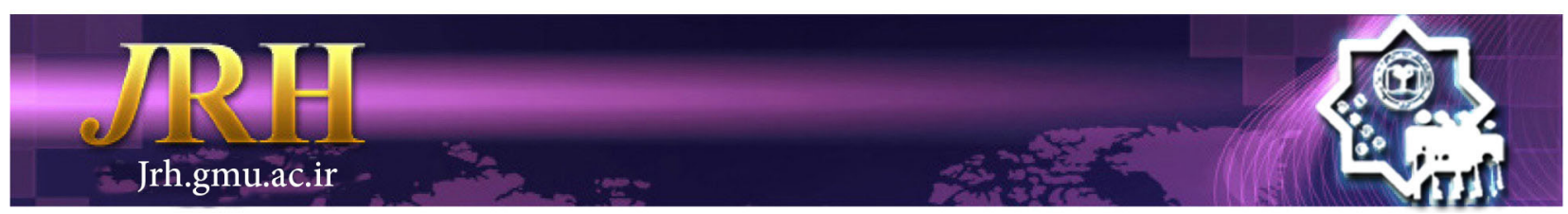

\title{
Relationship between treatment motivation, substance use, craving, withdrawal symptoms and health locus of control in addicted patients
}

Mahdi Moshki ${ }^{1}$, Mahmoud Panahi-Shahri ${ }^{2}$, Fatemeh Najarpour ${ }^{3}$, Marjan Mirzania ${ }^{1}$

\author{
Journal of Research \& Health \\ Social Development \& Health Promotion \\ Research Center \\ Vol. 8, No. 3, May \& Jun 2018 \\ Pages: $246-254$ \\ DOI: $10.29252 / j$ rh.8.3.246 \\ Original Article
}

1. Department of Public Health, School of Health Sciences; Social Development \& Health Promotion Research Center, Gonabad University of Medical Sciences, Gonabad, Iran

2. Department of Psychology, School of Humanities, Gonabad Payam-e-Noor University, Gonabad, Iran

3. Correspondence to: Fatemeh Najarpour, Department of Family Health, Social Development \& Health Promotion Research Center, Gonabad University of Medical Sciences, Gonabad, Iran

Email: F.najjarpour@chmail.ir

\section{Received: 8 Mar 2017}

Accepted: 20 Nov 2017

How to cite this article: Moshki M, Panahi-Shahri M, Najarpour F, Mirzania M. Relationship between treatment motivation, substance use, craving, withdrawal symptoms and health locus of control in addicted patients. $J$ Research Health2018; 8(3): 246- 254

\begin{abstract}
Increasing tendency to drug use is a major social problem, Treatment attempts, regardless of the motivation, are not complete. The study aimed to investigate the relationship between treatment motivation, substance use, craving, withdrawal symptoms and health locus of control in addicted patients. Research population this study included all male and female patients referring to the addiction treatment center. The convenience sampling was used to select the sample and the sample size was determined as 100 participants. Data collection tools consisted of questionnaires demographic characteristics, treatment motivation, craving, withdrawal symptoms and multidimensional Health Locus of Control. There was significant relationship between treatment motivation with craving, withdrawal symptoms and health locus of control and between treatment motivation with variables of sex, education, occupation and type of substance. There was no significant correlation between the components of the health locus of control, craving, withdrawal symptoms with sex, education, marriage and occupation. Regression results showed effective Perceived suitability of the treatment was 0.43 on the craving and Perceived suitability of the treatment and Problem recognition are respectively 0.40 and 0.23 , on the Withdrawal Symptoms. Considering the role of treatment motivation in reducing the return to drugs and the more willingness to treat and relapse less in people with internal control of control in future plans to address the problem of addiction and pushing addicts to treatment, the relevant variables have paid particular attention.
\end{abstract}

Keywords: Motivation, Substance Use, Health Locus of Control

\section{Introduction}

Addiction or substance abuse is a major social, health and psychological challenge in today' world and it has invaded human societies as the most crucial social harm [1]. Substance abuse is a non-adaptive model of substance use, which leads to many problems and adverse outcomes. It has a series of cognitive, behavioral and psychological symptoms [2]. The increasing rate of drug use in the world as a result of its accessibility has turned it to the second most common used substance after food. 'Except food, no other substance has 
penetrated nations than drugs,' said Lodding, a famous toxicologist [3]. Based on United Nations Office on Drugs, addiction is one of the world's four crises outlined and Iran has been introduced as a high-risk country in this regard [4]. Initial estimates in Iran shows that about 2 million people are taking drugs that considering a family of at least 5 persons, it gives a figure of about 10 million people (one out of every seven Iranians) directly involving in drugs [5]. According to information provided by Secretary of the National Congress of early prevention of addiction, age of onset of drug use and dependence is estimated to be 16 to 20 years old and at-risk age range includes 18 to 34 years [6]. Furthermore, Iran is located next to the largest drug producing country and it is regarded the main route for drug transfer to Europe. This has seriously incurred socioeconomic, political, cultural and health issues to Iran [7]. Craving, as a drug dependence experience, is a key concept contributing to the continued dependence, substance abuse and relapse [8]; it is an extremely persistent desire for substance use, causing psychological and physical sufferings such as lethargy, anorexia, anxiety, insomnia, aggression and depression if it is not satisfied [9]. The World Health Organization identifies craving as an underlying cause of drug dependence, loss of control and relapse [8]. Craving beliefs are significant factors contributing to failed treatment and relapse [10]. Studies report about $80 \%$ of individuals presenting for drug rehabilitation suffered a relapse within the first six months of treatment [11]. Research identified variables in patients such as cognition, readiness or motivation for treatment, demographic characteristics, duration of substance use and history of treatments as factors affecting relapse [12]. A study conducted on a population of young street drug users in 2005 reported aggravation of addiction and drug rehab facilities as the most significant factors enhancing addiction cessation [13]. Tawakoli-Ghuchani et al. found that $7 \%$ of the people who smoke occasionally and $43 \%$ of those who smoke habitually considered getting health as the reason for their desire to quit smoking; those who smoke habitually were also more eager to quit smoking because they felt addicted [11]. West et al. conducted a study to identify factors affecting smoking cessation in Britain and reported that motivation always affected smoking cessation [14]. Motivation is the need for a change felt by addicts that is demonstrated as response to positive and negative pressures for the change depending on the extent of which they have realized their problem [15]. Research also identified family pressure as the most influential factor and fear of legal problems as the least effective factor in motivating drug cessation [11]. Furthermore, a study suggested that highly addicted patients are seriously motivated quit smoking and people with higher education had more chances to do so. [16]. People's perceptions of the amount of control over their lives are different. This has attracted psychologists' attention for years and accordingly the concept of locus of control was developed as a psychological construct based on the framework of Rotter's in 1954 social-learning theory of personality [17]. Wallston et al. studied the Health Locus of Control (HLC) theory in 1970s; they observed patients with diabetes and identified medical service staff to be trying to change external HLC to internal HLC. Wallston and his wife stated that the purpose of all health instructors is to create internal locus of control in people. HLC is described as a degree of belief in a person that his/her health is controlled by internal or external factors [18]. People with external HLC regard factors such as doctors, chance, destiny and luck as determinants of definite consequences in their lives. In contrast, those with internal HLC directly attribute definite consequences as well as their health to their behaviors and actions [19]. People with internal locus of control have skills which are more adapted to the society and rarely demonstrate self-destructive behaviors such as smoking, drinking and substance abuse [20]. According to Sadr, patients with internal locus of control tend to drink less than those 
with external locus of control and recover more quickly [21]. Motivation plays a significant role in the treatment of drug dependent patients. Moreover, no study has so far been conducted in Iran to assess the relationship between motivation with substance use, withdrawal symptoms and HLC. The present study was therefore designed and implemented to investigate the correlation of treatment motivation with substance use, craving and HLC in patients presenting to rehabilitation clinics for addiction cessation.

\section{Method}

This was a correlation and descriptive-analytical study. Research population included all male and female patients referring to the addiction treatment center of Gonabad University of Medical Sciences in 2013. The convenience sampling was used to select the sample and the sample size was determined as 100 participants using Krejcie and Morgan table. The inclusion criteria were willingness to cooperate and participate in the study, age of 15 to 72 years, addiction to opium, crystal, or amphetamine and history of at least one relapse. Exclusion criteria included lack of cooperation in filling out the questionnaires. The required data were gathered using questionnaires on demographic characteristics, treatment motivation, craving beliefs, withdrawal symptoms and multidimensional HLC, which were completed by the subjects and then collected.

Treatment Motivation Scale (TMS): This questionnaire, which measures one's desire to engage in the treatment, includes four subscales (outcome expectancy, problem recognition, Perceived suitability of the treatment, Perceived legal pressure) and 24 items that are rated on a 7-point Likert scale (from 'completely disagree' to 'completely agree'). The validity and reliability of the data collection tool was confirmed by different studies [22,23]. This tool has not been used in domestic research so far. In order to assess its validity, the researcher and a number of professionals translated it separately and eliminated its challenges to create a unique form. In order to confirm the reliability and internal consistency, Cronbach's alpha of 0.56 was calculated for the subscale of perceived legal pressure, 0.61 for perceived suitability of the treatment, 0.69 for problem recognition, and 0.78 for outcome expectancy after completing the questionnaire by 60 subjects in the target group. It is worthy to note that the scores of subscales of this tool are calculated independently; that is, they are not summed.

Craving beliefs questionnaire: This self-rating scale was designed by Beck \& Wright in 1993. This scale measures drug craving beliefs and comprises 20 items. Each item is rated based on a 7-point scale (from completely disagree to completely agree). Reliability and validity of the questionnaire have been reported in literature [24]. For confirming the validity of the questionnaire, Pearson correlation coefficient of -0.28 has been reported [25] and for reliability, Cronbach's alpha of 0.84 and split-half of 0.81 have been calculated [8]. This study employed an exploratory factor analysis in which the items $1,3,4,5,6,7,8$, $9,12,13,14,16,17$, and 20 were associated with lack of control factor and the items 15 , 18 , and 19 were attributed to yielding to craving. Cronbach's alpha was calculated for lack of control and yielding to craving as 0.90 and 0.79 , respectively. To appraise the scale, the score of each subscale is estimated independently.

Subjective Opiate Withdrawal Scale: This questionnaire, which was developed by Handelsman, is an important tool to evaluate the intensity of withdrawal symptoms [26]. It consists of 16 items in which one's current feeling is rated based on a 5-point scale (5-1) ranging from very much to never and all scores are summed to give the final score. Najafi et al. confirmed the validity and reliability of the scale [27]; the present research also calculated Cronbach's alpha as 0.92 .

Multidimensional Health Locus of Control Scale: This scale was designed by Wallston et al. in 1978 and it is used to predict health behaviors based on one's beliefs. It consists 
of three versions of $\mathrm{A}, \mathrm{B}$, and $\mathrm{C}$. Forms $\mathrm{A}$ and $\mathrm{B}$ are used primarily to assess public health entities and form $\mathrm{C}$ is used for special occasions and can be used instead of form $A$ or form B for people who have health problems and medical conditions such as diabetes, cancer, etc [18]. The present study used form $\mathrm{B}$ of the scale, which contains 18 items on 3 subscales of internal (IHLC), powerful others (PHLC), and chance (CHLC). All the items have 6 options scored from 1 to 6 based on a Likert scale. One's score therefore can range from 6 to 36 for each subscale and the scores are not summed but estimated independently. Form B is a general HLC scale used to assess one's general health status. This tool does not specify a score as the cut-off point instead mean, median, or Z-Score is used for the measurements [17]. Face, content, concurrent, and construct validities and the reliability of this scale in a retest of peer assessments as well as internal consistency were confirmed by Moshki et al. [28]. This study calculated Cronbach's alpha as $0.69,0.60$, and 0.60 for each of IPC components.

After coordinating with Gonabad University of Medical Sciences and obtaining the permission of the technical assistant of the clinic, the patients were briefed about study objectives. After signing a consent form, the participants completed the questionnaires. The data obtained from the questionnaires were then analyzed in SPSS-20 using descriptive statistics (frequency, percentage), Pearson correlation test, and multiple regression.

\section{Results}

According to the descriptive findings of the present research, there were 100 respondents, comprising 87 males and 13 females; in terms of marital status, $83.9 \%$ of males and $61.5 \%$ of females were married while only around $8 \%$ were single. Moreover, $8 \%$ of males and $30.8 \%$ of females were divorced. Furthermore, the majority of respondents had high school diploma or below degree, while only $10-15 \%$ had an associate degree or higher. $78.2 \%$ of male respondents and $61.5 \%$ of female respondents were self-employed. Also, 2.3\% of males and $15.4 \%$ of females were farmer. The frequency distribution of respondents indicated that $57.5 \%$ of males used opium and $53.8 \%$ of females used crystal, while none of the females used amphetamine. While the majority of males $(71.3 \%)$ and females $(61.5 \%)$ used smoking as the method of substance use, none of them resorted to snorting. Among the treatment motivation subscales, the component "outcome expectancy" gave the highest

Mean score (51.02 \pm 5.72$)$ and the component "perceived legal pressure" gave the lowest one (11.51 \pm 2.74$)$. Among the dimensions of Health Locus of Control, the dimension "IHLC" has the highest mean score (31.27 \pm 3.90$)$ and the dimension "CHLC" has the lowest one $(21.86 \pm 6.43)$. Also among the components of Craving Beliefs Questionnaire, the component "compulsion" has the highest mean score $(65.94 \pm 20.21)$ and the component "negative deal" has the lowest one $11.29 \pm 6.81$ ).

Table 1 indicates a correlation between the components of treatment motivation, i.e. outcome expectancy, problem recognition and perceived suitability of the treatment, and the subscales of craving, withdrawal symptoms and HLC, while only perceived legal pressure was not correlated with craving and withdrawal symptoms.

The dimensions of treatment motivation contribute differently to the prediction of craving and withdrawal symptoms. The regression analysis was used to predict changes in the dependent variables (dimensions of craving and withdrawal symptoms) caused by the independent variables (treatment motivation dimensions) and to determine the contribution of each subscale of treatment motivation as the determinant of dependent variables. The present study used a stepwise method to enter the variables to the model one by one as long as the significance of the model is preserved at the $95 \%$ level of confidence, i.e. a 5\% error; otherwise the process is stopped. 
Table 1 Correlation matrix of major variables

\begin{tabular}{|c|c|c|c|c|c|c|c|c|c|c|}
\hline Variable & 1 & 2 & 3 & 4 & 5 & 6 & 7 & 8 & 9 & 10 \\
\hline \multicolumn{11}{|l|}{ 1. Outcome expectancy 1} \\
\hline 2. Problem recognition & $0.48^{* *}$ & 1 & & & & & & & & \\
\hline $\begin{array}{l}\text { 3. Perceived suitability } \\
\text { of the treatment }\end{array}$ & 0.15 & $0.25^{*}$ & 1 & & & & & & & \\
\hline $\begin{array}{l}\text { 4. Perceived legal } \\
\text { pressure }\end{array}$ & 0.19 & $0.29^{* *}$ & 0.02 & 1 & & & & & & \\
\hline 5. Coercion & -0.14 & -0.12 & $-0.39^{* *}$ & 0.12 & 1 & & & & & \\
\hline 6. Negative deal & $-0.29^{* *}$ & $-0.31^{* *}$ & $-0.44^{* *}$ & 0.11 & $0.63^{* *}$ & 1 & & & & \\
\hline 7. Withdrawal symptoms & $-0.24^{*}$ & $-0.33^{* *}$ & $-0.45^{* *}$ & 0.02 & $0.53^{* *}$ & $0.68^{* *}$ & 1 & & & \\
\hline 8. Chance & $-0.30^{* *}$ & -0.12 & $-0.25^{*}$ & $0.21^{*}$ & $0.534^{* *}$ & $0.455^{* *}$ & $0.438^{* *}$ & 1 & & \\
\hline 9. Internal & 0.02 & $0.27^{* *}$ & -0.02 & $0.36^{* *}$ & 0.152 & 0.040 & 0.052 & $0.43^{* *}$ & 1 & \\
\hline 10. Powerful others & $0.36^{* *}$ & $0.50^{* *}$ & $0.36^{* *}$ & $0.31^{* *}$ & -0.158 & $-0.241^{*}$ & $-0.267^{* *}$ & 0.03 & $0.35^{* *}$ & 1 \\
\hline
\end{tabular}

"p $<0.05, \quad{ }^{* *} \mathrm{p}<0.01$

According to the result, only the treatment motivation subscale of perceived suitability of the treatment, when added to the equation, significantly predicted the dependent variable of craving in the regression model. The multiple correlation between the independent variable 'perceived suitability of the treatment' and dependent variable 'craving' was found to be 0.43 and as small as $18 \%$ of the changes in 'craving' is justified by the regression line. Moreover, 'perceived suitability of the treatment' and 'problem recognition' were added to the equation because they significantly contributed to the prediction of the dependent variable 'withdrawal symptoms' in the regression model. In the first model, 'perceived suitability of the treatment' explained $20 \%$ of variance of withdrawal symptoms' while upon the entrance of 'problem recognition' to the second model, the amount of variance explained increased to $24 \%$ (Table 2).

Table 2 Stepwise regression analysis model of variables motivational treatment, craving and withdrawal symptoms

\begin{tabular}{lccc}
\hline \multirow{2}{*}{ Dependent variable } & \multirow{2}{*}{ Predictor } & \multicolumn{2}{c}{ Multivariate regression analysis } \\
\cline { 3 - 4 } & & $\mathrm{r}$ & $\mathrm{R}^{2}$ \\
\hline Craving & $\mathrm{PT}$ & 0.43 & 0.18 \\
\hline \multirow{2}{*}{ Withdrawal symptoms } & $\mathrm{PT}$ & 0.45 & 0.20 \\
& $\mathrm{PR}$ & 0.50 & 0.24 \\
\hline PT= Perceived suitability of the treatment & & \\
PR= Problem recognition & & &
\end{tabular}

Results show that one unit of change in the standard deviation of 'perceived suitability of the treatment' caused a change of 0.43 in 'craving', indicating that the former variable affects the latter one by 0.43 . Similarly, one unit of change in standard deviation of 'perceived suitability of the treatment' and 'problem recognition' respectively led to 0.40 and 0.23 changes in standard deviation of 'withdrawal symptoms (the best predictor model is shown). Variables with higher absolute values of standard coefficients have greater effects on the changes of the dependent variable. Therefore, 'perceived suitability of the treatment' affects the changes of 'withdrawal symptoms' by 
0.40 , which is more than the effect of the other variable. Among the components of treatment motivation, 'perceived suitability of the treatment' is therefore regarded as the best predictor of 'craving' and 'withdrawal symptoms' (Table 3).

\begin{tabular}{lccccc}
\multicolumn{7}{l}{ Table 3 Predictor variable regression coefficients } \\
\hline Dependent variable & Predictor & B & SE & Beta & sig \\
\hline Craving & PT & -2.09 & 0.44 & -0.43 & 0.001 \\
\hline \multirow{2}{*}{ Withdrawal symptoms } & PT & -1.02 & 0.23 & -0.40 & 0.001 \\
& PR & -0.75 & 0.30 & -0.23 & 0.014 \\
\hline
\end{tabular}

\section{Discussion}

The present study was conducted to determine the correlation of treatment motivation with substance use, craving, withdrawal symptoms and HLC in patients presenting to the habilitation clinic in the city of Gonabad. We observed the significant relationship of treatment motivation with craving and withdrawal symptoms. We also found a negative correlation between outcome expectancy and problem recognition subscales with negative deal component of the craving scale. Perceived suitability of the treatment, as a component of treatment motivation, was negatively correlated with compulsion and negative deal components, while perceived legal pressure did not have a significant relationship with any of craving components. Outcome expectancy, problem recognition and perceived suitability of the treatment were negatively correlated with withdrawal symptoms while perceived legal pressure was not significantly correlated with withdrawal symptoms. The results obtained by Kajbaf et al. were consistent with the findings of the present study, indicating that individual motivation strongly contributes to embarking on addiction cessation; as a result, it encourages addicts to start the treatment and reduces the frequency of relapses [29]. The results of the present study are however incompatible with those found by Karimi Talabari, Battjes and Bahrami. According to Karimi Talabari et al. in 2012, high suggestibility of patients causes them to be easily affected by others, and this peer pressure sometimes makes them not continue the treatment, change the treatment type or return to drugs. Therapeutic conditions and regulations put such pressure on the patients that they may not tolerate the pressures and abandon the treatment, especially if they are unstable or unmotivated [30]. Battjes et al. demonstrated the negative correlation of perceived legal pressure with treatment motivation and craving [31]. Bahrami et al. suggested that a change in attitudes will double the patient's intrinsic motivation for withdrawal and reduces both perceived legal pressure, particularly family pressure, and the anxiety imposed on the family. Training innate motivation therefore plays a significant role in the reducing addicts' positive attitude to opioids and increasing the success probability of the treatment, resulting in no subsequent craving [32]. We observed a significant correlation between treatment motivation and HLC. The findings also suggested a positive correlation between all dimensions of treatment motivation and internal factors of HLC, while problem recognition and internal factors had the strongest relationships. On the other hand, outcome expectancy and perceived suitability of the treatment were not correlated with the effective factors of HLC. All the components of HLC were positively related to the perceived legal pressure as one of the components of treatment motivation. The results obtained in the study of Richard et al. in 2006 showed that adolescents with internal locus of control craved drugs and returned to smoking and substance use and they were less motivated to continue and maintain their treatment [33]. Lefcourt et al. believed that people with external locus of control face more failures in the treatment than those with internal locus of control and they have more difficulties in social interactions; they react aggressively and 
irritably to the social pressure, their motivation is affected by perceived legal pressure, and this often returns them to drugs. People who have internal locus of control have more adapted skills in relation to the society and they are more vulnerable to self-destructive behaviors such as smoking, drinking, and drug addiction [20]. The findings suggested no correlations or significant relationships between treatment motivation components and age and income. It means that age and income cannot affect treatment motivation. A positive correlation was however seen between gender, level of education, occupation, marital status and drug type used and the treatment motivation. Behdani et al. also found a significant difference between males and females in terms of willingness to participate in the treatment, indicating higher motivation in males than in females [34]. The results obtained by Tucker et al. in 2004 denoted no significant role of age, gender and desire to receive help in the prediction of treatment readiness [35]. Different measurement tools, different sample sizes and research populations, diverse study goals and various analysis methods might have caused the difference in the findings. Our findings also suggested no significant correlation between the components of craving, withdrawal symptoms and substance use and age and income. The family with and addict member was the only demographic detail being positively correlated with withdrawal symptoms. It means having an addict in the family can positively affect craving and withdrawal symptoms. The present study did not find a significant relationship between the intensity of drug dependence and substance use and the duration of retention in treatment or duration of withdrawal, which is inconsistent with the results of a study conducted by Hosseini et al., who reported a significant relationship between the duration of retention in treatment and the drug type and consumption method [36]. The present research did not report any relationships between demographic details and HLC. Locus of control, as an important personality trait, plays a significant role in one's adaptation. It is also a feature that can be controlled by an individual. Changing the locus of control from an external to internal type can therefore increase adaptability, enhance the mental health level and decision making power in people [27]. The results obtained are not consistent with the findings of Cheldie et al. because they stated that married patients with external locus of control are more likely to return to drugs than single patients with internal locus of control. Furthermore, they believe that the relapse in patients, aged 20-30, with internal locus of control is more frequent than in the older patients with internal locus of control as was the case in the comparison of patients with lower degrees of education with those who are highly educated and have internal locus of control. He reported a relationship between the family experience and reconversion to addiction and also between having an addicted family member with locus of control [37]. No significant relationship was observed in this study between age and gender and HLC beliefs, which was consistent with the findings of Moshki et al. They considered age and gender homological variables in their study and found no significant correlation between these variables and self-esteem and HLC beliefs [38]. Owing to legal and social sensitivities of the addiction issue, the data collected were vulnerable to response bias of participants, which is regarded as a limitation in the present study. The scope of the study was also limited to public rehabilitation clinics, with a limited sample size consisting of more males than females. It is therefore suggested that similar studies be conducted in private clinics so that more witnesses are collected to confirm the hypotheses of this study.

\section{Conclusion}

Considering the findings of the study and the role of treatment motivation in reducing the return to drugs and the more willingness to treat and relapse less in people with internal control of control in future plans to address the problem of addiction and pushing addicts 
to treatment, the relevant variables have paid particular attention.

\section{Acknowledgements}

The authors would like to thank the sincere cooperation of the officials and staff of the addiction treatment center of Gonabad University of Medical Sciences.

\section{Contribution}

Study design: MM, MP, FN, MM

Data collection and analysis: MM, MP, FN

Manuscript preparation: MM, MM

\section{Conflict of Interest}

"The authors declare that they have no competing interests."

\section{Funding}

The authors received no financial support for the research, authorship and/or publication of this article.

\section{References}

1- Shahriari Sh, Dastjerdi R, Hojjat-Zadeh N, Keikhai R, Ramazani A. Family function on tendency students towards addiction substance abuse. Journal of Zabol University of Medical Sciences and Health Services2014; 5(4): 59-67.

2- Dehghani K, Zare A, Dehghani H, Sedghi H, Poormovahed Z. Drug abuse prevalence and risk factors in students of Shaheed Sadoughi university of medical sciences, Yazd. Journal of Shahid Sadoughi University of Medical Sciences2010; 18(3): 164-9.

3- Danesh P, Feizolahi A, Heidari S. The status of drug abuse consumption and distribution in Ilam Township. Ilam Culture2014; 15(42,43): 166-81.

4- Seyed-Javadi M, Seyed-Mousavi A, Mohammadi R, Brahimi F, Seyed-Javadi M. Epidemiology of drug abuse in self-introduced addicts to addiction treatment clinic in Ardabil in 2012. National Congress on Addiction Science 2013; Tehran, Razi Hall: 622.

5- Naghizadeh M, Rezaei Z, Zarei F, Firoozi E, Ahmadi D. Pattern of illegal use of drug in substance abuse control clinic of fasa, Iran (2009-2011). Journal of Fasa University of Medical Sciences2013; 3(4): 305-3011.

6- Tafreshi H, Addiction rates in Iran. Razi2011; 23(2): 49-56.

7- Sahebi L, Vhidi RG, Ali-Hosseini S, Mousavi H. Mental health status of intravenous drug addicts in drop in centers (DIC) of East Azarbaijan, north western part of
Iran. Journal of Fundamentals of Mental Health2010; 12(47): 584-895.

8- Rahmaniyan M, Mirjafari A, Hasani J. The relationship between craving and attentional bias in opioid dependent, relapsed and abstinent individuals. Iranian Journal of Psychiatry and Clinical Psychology2006; 12(3): 216-22.

9- Babaiee Z, Hasani J, Mohamadkhani Sh. The effectiveness of dialectical behavior therapy based emotion regulation skill training in substance abusers craving: a single subject study. Journal of Clinical Psychology2012; 4(3): 33-41.

10- Haji-Alizadeh K, Bahreinian SAM, Naziri GH, Modares-Gharavi M. The role of cognitive variables, metacognitive dimensions and emotions in substance abuse behaviors. Advances in Cognitive Science2009; 11(3): 1-12.

11- Tawakoli Ghuchani H, Shojaei Zadeh D, Mazloum SR. Comparative study of factors associated with addiction withdrawal in clients referring to drug stop clinics of northern Khorasan (Iran) in 2007. Scientific Journal of Ilam University of Medical Sciences2009; 17(2): 32-43.

12- Kikhavandi S, Menati R, Kassani A, Menati W. Associated factors with addiction relapse in patients of referring to addiction tretment centers in Ilam: a casecontrol study. Journal of Ilam University of Medical Sciences2015; 22(6): 165-173.

13- Steensma C, Boivin JF, Blais L, Roy E. Cessation of injecting drug use among street based youth. Jornal of Urban Health2005; 82(4): 622-37.

14- West R, McEwen A, Bolling K, Owen L. Smoking cessation and smoking patterns in the general population: A 1-year follow-up. Addiction2001; 96(6): 891-902.

15- Jafari M, Shahidi Sh, Abedin A. Comparing the effectiveness of cognitive-behavioral therapy and trans-theoretical model on improving abstinence selfefficacy in substance dependent adolescents. Journal of Research Behavioural Sciences2009; 7(1): 1-12.

16- Targowski T, Grabowka P, Rozynska R, From S, Mierzejewska J, Niedzialkowski P. Comparative analysis of Nicotine dependence and motivation to quit smoking in patients with bronchial asthma or COPD. Przeglad Lekarski2004; 61(10): 1046-8.

17- Moshki M, Baloochi BT, Cheravi K. The relationship of postpartum depression to health control beliefs and demographic factors. Journal of Zanjan University of Medical Sciences2014; 22(92): 74-85.

18- Wallston KA, Wallston BS, DeVellis R. Development of the multidimensional health locus of control (MHLC) scales. Health Educ Monogr1978; 6(2): 160-170.

19- Zahednezhad H, Poursharifi H, Babapour J. 
Relationship between health locus of control, slip memory and physician-patient relationship with adherence in Type II diabetic patients. Journal of Shahid Sadoughi Universith of Medical Sciences2012; 20(2): 249-58.

20- Lefcourt HM. Locus of control: current trends in theory and reaserch. (2nd). Hllsdale, NJ: Erlbum; 1982.

21- Sadr S. Failing common drug treatment in psychiatry. Iranian Journal of Psychiatry and Clinical Psychology2011; 16(3): 53-62.

22- Joosten EAG, De Jong CAJ, De Weert-Van Oene GH, Sensky T, Van Der CPF. Shared decision-making reduces drug use and psychiatric severity in substancedependent patients. Psychother Psychosom2009; 78(4): 245-53.

23- De Weert-Van Oene GH, Schippers GM, De Jong CA, Schrijvers GJ. Retention in substance dependence treatment: the relevance of in-treatment factors. J Subst Abuse Treat 2001; 20(4): 253-61.

24- Beck AT, Wright FD, Newman CF, Liese BS. Cognitive therapy of substance abuse. New York: Guildford press; 1993.

25- Ehrman RN, Robbins SJ, Bromwell MA, Lankford ME, Monterosso JR, O'Brien CP. Comparing attentional bias to smoking cues in current smokers, former smokers, and non-smokers using a dot-probe task. Drug Alcohol Depend2002; 67(2): 185-91.

26- Handelsman L, Cochrane KJ, Aronson MJ, Ness $\mathrm{R}$, Rubinstein KJ, Kanof PD. Two new rating scales for opiate withdrawal. Am J Drug Alcohol Abuse1987; 13(3): 293-308.

27- Najafi K, Amir-Alavi C, Zarrabi H, Mohammadzadeh A, Khodaei ES, Salajegheh A. Survey the prevalence of recurrence in ultra rapid opiate detoxification in opiate and heroin dependents. Journal of Guilan University of Medical Sciences2008; 17(67): 55-64.

28- Moshki M, Ghofranipour F. Iranian version of Form $\mathrm{B}$ of the multidimensional health locus of control scales among the youth. Journal of Clinical Nursing2011; 20(11-12): 1561-7.

29- Kajbaf MB, Rahimi F. Comparision of addicts personal/social motives and social capital among treatment groups in city of Isfahan. Journal of New Educational Approaches2011; 6(1): 125-48.

30- Karimi Talabari Z, Noor Khajavi M, Rafiei H. Reasons of methadone maintenance therapy drop out in clients of Iranian National Center for Addiction Studies (INCAS): a qualitative study. Iranian Journal Psychiatry and Clinical Psychology2013; 18(4): 299-309.

31- Battjes RJ, Gordon MS, OGraady KE, Kinlock TW, Carswell MA. Factors that predict adolescent motivation for substance abuse treatment. J Subst Abuse Treat2003; 24(3): 221-32.

32- Bahrami F, Mazdyan A, Husseinial-Madani A. The effectiveness of teaching problem solving skillsand decision-makingon reducing positive attitude Addicts. Quarterly Journal of Research on Addiction2013; 7(25): 57-72.

33- Eiser JR, Eiser C, Gammage P, Morgan M. Health locus of control and health beliefs in relation to adolescent smoking. Addiction 1989; 84(9): 1059-65.

34- Behdani F, Hebrani P, Arshadi H. Epidemiological characteristics of patients in methadone maintenance treatment, admitted in Hospital, Mashad (20052006). Quarterly Journal of Fundamental of Mental Health2007; 9(33-34): 53-59.

35- Tucker JA, Vuchinich RE, Rippens PD. A factor analytic study of influences on patterns of helpsseeking among treated and untreated alcohol dependent persons. J Subst Abuse Treat2004; 26(3): 237-42.

36- Haj-Hosseini M. Comparing the attributional theory (learned helplessness model) among addicted and non-addict youths of the city of Yazd. Journal of Research on Addiction2003; 1(3): 133-48.

37- Kaldi A, Mahdavi R. The role of internal and external locus of control in relapse of addiction in occupational therapy camp of Zanjan. Social Welfare2003; 3(9): 307-34.

38-Moshki M, Nouri-Sistani M, Peyman N. Association of health locus of controland self-esteem with physical activity in university students. Journal of Sabzevar University of Medical Sciences2009; 16(3): 142-9.

Copyright(C) 2016 ASP Ins. This open-access article is published under the terms of the Creative Commons Attribution-NonCommercial 4.0 International License which permits Share (copy and redistribute the material in any medium or format) and Adapt (remix, transform, and build upon the material) under the Attribution-NonCommercial terms. 